"Le nid de l'homme, le monde de l'homme, n'est jamais fini. Et l'imagination nous aide à le continuer."

(Gaston Bachelard, La Poétique de l'espace)

"En el palacio que imperfectamente exploré, la arquitectura carecía de fin. Abundaban el corredor sin salida, la alta ventana inalcanzable, la aparatosa puerta que daba a una celda o a un pozo, las increíbles escaleras inversas, con los peldaños y balaustrada hacia abajo."

(Jorge Luis Borges, "El inmortal”) 


\section{INTRODUCTION: The Arkhitekton}

"No being exists or can exist which is not related to space in some way" (Isaac Newton)

Jorge Luis Borges once remarked in a conversation with Alifano (1983) that reality needs a centre, a map, a structure; without architecture, there is no universal coherence. Thus even the labyrinth - a construction designed to confuse man but with a logical architectural form - is nevertheless an image of hope. "Somehow we are saved", said Borges (Alifano, in Mualem 2012:74), as long as the real can claim 'an architecture'.

With this statement, Borges emphasised the necessity of believing in a constructed (or constructible) reality for this reality to be manageable: only then does cosmos escape chaos. This philosophy of reality as potentially constructed by the subjects who inhabit it - a vision far removed from the objective, immutable, positivistic 'real' - sums up the relativist postmodern Zeitgeist of which Borges' fictions and essays have been precursors. What is even more interesting is that this idea of a constructed real is not so recent after all: in fact, it can be traced back to the Greek root of the word 'architect' (arkhitekton). From the Greek words arkhe ("the beginning" or "origin"), arkhon ("the ruler") and tekton ("builder", "creator of artifice"), one of the multiple meanings of this term represents the origin transformed by the architect into a defined, and thus habitable, space for the human being. By setting boundaries to the world the architect constructed a space in which man could dwell. The architect in Western civilisation had the power and skill (tekton) to manipulate the origin (arché) into 'liveable' space. Moreover, the etymology suggests that the action of 'building' can be understood not only as giving material shape to physical space but also as 'raising' 
reality from the origin, hence the origin of architecture as a divine activity in Western mythology (cf. Azara 2005). This not only advances the foundational idea of reality as a human construction but also asserts the importance of spatiality in human experience: architecture is a structuring principle of reality. John Ruskin captured this beautifully at the opening of The Poetry of Architecture with the statement: "no man can be an architect, who is not a metaphysician" (1905:1).

Space - in particular in the ways we articulate it - is a means by which we organise the world. This, in turn, introduces the category of space as a man-made construction. Such an understanding of space represents a radical departure from the tradition that has predominated in Western culture for centuries, whereby space was regarded as a simple container in which the human being dwells: a given, objective and measurable entity, perceptible only in its mathematical dimensions. Space, according to the previous etymological reading of the word 'architect' (and architecture), is constructed by the human for the human.

This book, anchored as it is in a parallel between architecture and literature as arts of building an artificial reality, is born from both an observation and a hypothesis. The observation is that the literary Fantastic - understood here as the incursion of an impossible element into a realistic frame shared by narrator and reader - is not found only in the haunted houses, remote castles and further gothic enclaves of the late $18^{\text {th }}$ and early $19^{\text {th }}$ century; neither is it limited to its migration into the city, as occurred at the turn of the $19^{\text {th }}$ century with the acceleration of Modernity, nor restricted to appearances in such contemporary spaces as metro stations or airports. There is a modality of the Fantastic which, while first envisaged in a few short stories of the $19^{\text {th }}$ century such as "The Fall of the House of Usher" (E.A. Poe 1839) and greatly influenced by the metaphysical Fantastic of Jorge Luis Borges and the everyday Fantastic of Julio Cortázar, is consolidated within the corpus of the last decades. In 
the texts belonging to this modality, physical space does not provide the frame in which the Fantastic will appear; instead space $i s$ the Fantastic. Holes that render invisible those who happen upon them, structures that entrap and devour the individual, elastic constructions separated by fluctuating distances, intermittent buildings that disappear and reappear as they please, tunnels that compress distances, compartments that invert the logical order of the big in the small, spaces that suddenly multiply... these are some of the examples of this textual phenomenon. In this modality, the impossible supernatural element does not take place in space but is rather an event of space, bound to some architectural element or to the (normal, logical) physical laws governing this dimension. Without a doubt, this phenomenon has textual precedents. However, it is only from the late seventies onwards that its presence has been observed within a multitude of cultural and literary traditions. Furthermore, it is in this postmodern context, when the dimension of space has been re-evaluated from sociohistorical, scientific, philosophical and literary angles, that this literary phenomenon is most in need of investigation.

The hypothesis, on the other hand, stems from a philosophical concern, one concerning the linkage between physical space and the weakening experience of reality in the postmodern context. In the following paragraphs the relevant aspects of this context are outlined in order to illustrate how this assumption took shape.

\section{The 'Spatial Turn' in Postmodernity}

Over the past few decades a large number of literary scholars (e.g. McHale 1987; Ryan 1991; Álvarez Méndez 2002; Ainsa 2006; Westphal 2007, 2011a) have demonstrated how the reconfiguration in our way of understanding space in the late $20^{\text {th }}$ century has not only accentuated the significance of narrative space but has also prompted a reconfiguration 
of the category of the real, which inevitably affects its counterpart, the fictional. This has given birth to a form of literature bearing the label of 'the postmodern'.

The terms 'Postmodernism' and 'Postmodernity' have been the centre of polemic discussion in literary and cultural theories, the first term tending to being employed as an aesthetic movement while the latter is often associated instead with the cultural and historical aspect. For the purpose of this book, this conceptual distinction will be ignored since both aspects are not easily separated one from the other, in particular with interdisciplinary studies. While it is not my intention to contribute to this debate, it may be useful to specify what is to be understood by 'postmodern' in this book and then to apply this definition to the more constricted and relevant frame of the postmodern Fantastic. I will briefly discuss two wellestablished approaches. McHale in Postmodernist Fiction (1987) defines Postmodernism as a shift from the epistemological concern shaping Modernism (How can knowledge be attained?) towards a characteristic ontological one (What is 'real'? What is not 'real'? What is a world? How does a world come into being?), this change of dominant being particularly present within cultural and aesthetic productions from the late sixties until the present day. Lyotard's perspective on the postmodern (1979), in contrast, concentrates on epistemological doubt. His theory of the end of Grand Narratives calls into question the 'truth' of any official and universal discourse. Lyotard's understanding of reality as narrative suggests that subjectivity is inherent in any discourse aimed at legitimising history and other fundamental epistemological constructions of Western culture. Narrative, then, is always an incomplete testimony of reality, and since our means of expressing the real is narrative, all views on reality are necessarily incomplete. The epistemological and ontological dominants are in many cases not easily abstracted from each other, in particular in the case of the postmodern Fantastic; a preoccupation with both the nature of reality (leading to an re-examination of the real/fictional) as well as with our limited means of gaining truth about reality dominate the 
themes and plots of the postmodern Fantastic, as the following chapters will show.

Positivist claims of an objective reality that is external to the individual are today tenuous, given that even scientific research has now been proven to be vulnerable to the subject carrying out the research. The major breakthrough originated with Albert Einstein's Theory of Relativity (1905 and 1915), when Einstein demonstrated that time and space were inextricably bound up with one another, redefining the structure of physical reality into a four-dimensional space-time continuum. Space was found to be affected not only by time but also by mass, in particular by the presence of high density mass, causing it to wrap. This was the end of the Newtonian certainty of time and space as absolute, uniform categories, independent of the physical contents of the universe. Newton's perspective, which had dominated the scientific scene for over three hundred years, yielded to the relativist model. Even more influential, from a philosophical point of view, were the later discoveries of quantum mechanics, in particular Heisenberg's Principle of Indeterminacy (1925). As is well known, this principle establishes that at a subatomic level the behaviour of the object being monitored is necessarily impacted by the presence of the observer. This was a definite shift away from positivistic idealism of the $19^{\text {th }}$ century, with science now forced to recognise its own limitations and paradoxes.

In consequence, the idea of an attainable, absolute model of knowledge vanished, to be replaced by a view of the real as inevitably deriving from how the subjects in it perceive it. Once more, as in the figure of the arkhitekton, the subject regained the ability and responsibility of being the artifice of his/her own reality.

Relativism was, however, to propagate beyond the realm of physics. Einstein's Nobel Prize formula concerning the equivalence mass-energy was to be a crucial step towards the atomic and digital age. In just a few decades, its repercussions infiltrated everyday life in the form of a technological revolution that deeply affected conceptions of distance and location 
by, for example, facilitating the transmission of large amounts of information across long distances in a matter of seconds. Parallel to this, phenomena of wide reaching impact like the atomic bomb accelerated a global consciousness and prompted a redefinition of human geography. The Second World War triggered large volumes of immigration across geopolitical borders while the Cold War was to see the rapid emergence of a succession of states as well as further geopolitical restructuring, boosted by the fall of the Iron Curtain and the enlargement of the EU. In the socio-urban domain, the reconstruction of the post-war urban landscape originated a new model of contemporary city (cf. "Postmetropolis", Soja 2000). Simultaneously, in the historical domain, the process of de-colonisation encouraged advocacy for the end of a single centre of reference in favour of a multiplicity of points of view. This concurrence of events was to render it increasingly evident that notions of identity and culture could not be ascribed to a single stable territory. Geography no longer referred only to the physical place in which the human being was located; it also encompassed a variety of dimensions intertwined.

Not only have advances in physics and a series of historical confluences reconfigured our vision and experience of space, they have also given rise to an unprecedented interest in the dimension of space within academic discourses. While never ignoring the fact that we are temporally-bound beings, during the past few decades the so-called Spatial Turn in the Humanities and Social Sciences has increasingly emphasised the importance of spatiality in understanding the history of the human being and of its artistic products. In a famous conference in 1967 entitled "Des Espaces Autres", Michel Foucault predicted that we were entering an era in which thinking in spatial terms would be key to understanding the increasing prominence of the simultaneous and the juxtaposed. The Spatial Turn has ensured that space - a physical and architectonic dimension, but also an intimate (Bachelard 1958), social (Lefebvre 1974, De Certeau 1980, Augé 1992), political (Foucault 1967), urban (Soja 
1989), sexual (Massey 1994), cultural (Jameson 1990) and economic (Harvey 1990) category - is no longer a neutral concept and cannot be considered independent from that which it contains, and therefore neither can it be considered as immune to historical, political and aesthetic changes. Whereas from a mathematical perspective space is a relatively stable category, from a humanist angle space is a category with history. Proof of this lies in the diverse ways in which space was conceived of throughout Antiquity, the Middle Ages, the Renaissance, Modernity or Postmodernity, as well as in the different paradigms of space in philosophy (for example the approximations by Aristotle, Leibniz, Kant or Heidegger) and in the history of physics (for example the theories of Newton and Einstein). What is more, as Jammer (1954) and Disalle (2006) have shown, even the relatively objective concept of space in physics has evolved in tandem with these diverse philosophical propositions; and as such the study of space has been reasserted in human science as a scholarly field requiring and creating connections across disciplines.

In the domain of literature, the relatively recent interest in the spatial dimension in Literary Theory breaks from a tradition that prioritised time over space. This primacy of the temporal was to a large extent due to the generic distinction between spatial and temporal arts. Lessing's influential essay "Laocoon: or the Limits of Poetry and Painting" (1766) was one of the pioneer essays in positioning literature within the temporal. From this perspective, the literary text is conceived of as a succession of words, sounds and events while, for example, sculpture or painting instead offer objects juxtaposed in space and simultaneously apprehended. Space in narratives often seemed to have no further function than to supply a general background for the action.

This restriction has been challenged since the middle of the $20^{\text {th }}$ century as manifold contributions, such as Mikhail Bakthin's chronotope (1975), Franco Moretti's literary cartographies (1998, 2005), Marie-Laure Ryan's cognitive approach to narrative (1991, 
1993), Bertrand Westphal's geocritical method (2007) and Robert Tally's interdisciplinary summary on human spatiality (2013), have convincingly argued that the selected, described, represented and symbolised spaces are of central value to literary analysis.

However, it appears that this Spatial Turn in Literary Theory is not yet consolidated in the scholarship of the Fantastic. On the one hand, existing methodologies on space in narrative (Hamon 1972; Ronen 1986; Soubeyroux 1993; Pimentel 2001; Álvarez Méndez 2002) traditionally centre their approaches on realist literatures. The Fantastic, if mentioned at all, appears as an ambiguous category and very often refers to any form of supernatural intervention. The result is that there is no comprehensive model for analysing space in relation to the Fantastic ('Fantastic' considered as a particular narrative form and not as a meta-category for the imaginary or supernatural; see Chapter 1).

On the other hand, while there are plenty of studies in which 'fantastic space' acts as a metaphor for a large variety of aspects - such as the transgression of literary genres, the unconscious or the confrontation with the domain of the other - the list of studies focusing on space as physical dimension recreated in the fantastic text is extremely limited. Campra (2001) and Roas (2011) remind us of the central function that the dimension of space occupies within the literature of the Fantastic: spatial references and detailed descriptions of places are key devices that enable the reader to identify with the space that is presented as realistic. That allows for the generation of the impression of verisimilitude required prior to the fantastic transgression. As regards space as theme, the spatial category is present from the foundational studies by Castex (1951), Caillois (1975) and Todorov (1975). However, even in these works space appears bound to time in one interdependent category, forming the cluster of "space-time distortions". Following on from this intellectual move towards exploring the intersection between time and space, some more recent studies (Aguirre 1990; Fournier Kiss 2007) have identified the thematic potential of settings. Such studies emphasise 
the chronotopic nature of certain settings and analyse the evolution of the Fantastic according to the function and symbolism of these settings. However, is narrative space to be limited to those referential or chronotopic values? What new perspectives can be obtained by foregrounding spatiality in the fantastic text? This book, dedicated to exploring the linkage between the Fantastic and space in the postmodern context, has been inspired by these questions.

\section{The Postmodern Fantastic as a Phenomenon of Space}

The production of a large volume of texts questioning the objective nature of reality has given rise to a specific form that has been labelled as 'postmodern Fantastic' (Grossman 2000; Horstkotte 2004; Roas 2011). With Jorge Luis Borges and, subsequently, Julio Cortázar as founding fathers, the postmodern Fantastic was to consolidate across different literary traditions from the 1970 s onward. What gives coherence to the texts that fall under this category is the following: although the impossible element still operates in a presumed 'reality' shared by both narrator and reader, this reality is revealed as chronically unstable and weak, as a construction marked by codes of routine and social conventions. This ontological weakening materialises in the form of specific, recurrent traits. While the next chapters will explore the question in more detail, it is useful here to consider a few examples that illustrate these traits. A very clear example is the reaction of the protagonists towards the supernatural. The postmodern protagonist often reacts with very little surprise or consternation, in sharp contrast to the terrified characters found in the Fantastic of Hoffmann, Poe or Maupassant. In the postmodern Fantastic, more often than not, the character confronted with the supernatural event accepts the Impossible with resignation, in a natural manner, as just one of the many oddities of this eccentric world in which he/she lives. 
It is important to emphasise that the postmodern Fantastic, just as is the case with the Postmodern more generally, is not a radical break from the tradition of the Fantastic founded in the $18^{\text {th }}$ and $19^{\text {th }}$ century. I am therefore inclined to avoid the term 'neofantastic' (Alazraki 1983), which appears to have left an imprint within the current academic scene, as it does not seem to reflect this continuity. As the analysis offered by this book will show, the postmodern Fantastic not only incorporates new motifs but also integrates traditional motifs, though with a distinct renovating impulse.

The banalisation of the fantastic event is often accompanied in the Fantastic by another typically postmodern literary technique: that of metafiction. The prevalence of this technique can be explained in relation to the Linguistic Turn, which saw a growing distrust of the ability of language to refer to reality. Once again, a fundamental precursor of this model of the Fantastic can be found in the fiction of Borges, for example in his use of intertextuality to question the notions of originality, authenticity, truth and of reality, a paradigmatic example being “Tlön, Uqbar, Orbis Tertius” (1961).

The critical attention paid by scholars of the Fantastic to the Linguistic Turn and the contrast with the lack of attention given to the Spatial Turn led me to formulate the following questions:

Just as the Linguistic Turn profoundly affected the Fantastic in terms of themes, motifs and plot structures ("the Fantastic of Language", Erdal Jordan 1998; Campra 2001; Casas 2010; Rodríguez 2010), could a similar role not be attributed to the Spatial Turn? Does space - shown to be a fundamental category of human experience of reality as well as a tool for conveying the impression of textual realism - not act as a vehicle to reflect this turn in an aesthetic form? And if so, in what way?

These questions are as yet unexplored within the critical corpus of the Fantastic. Over the last few decades there has been an unprecedented rise in the number of short stories in 
which the impossible element is bound to space: space not as scene of actions but as the impossible element in the story. This transgression of space disrupts the comforting notion of space as objective entity in favour of the idea of space as constructed and conventional. Conceptualising and contextualising this phenomenon is the main contribution of this book.

\section{The Postmodern Fantastic as a Comparative Fantastic}

A fundamental factor in deciding on a comparative angle was the realisation that the phenomenon of spatial transgression relegated the cultural markers of each literary tradition to a secondary position. Paradoxically it was of little importance whether a text belonged to the French, Spanish, Peruvian or Belgium Fantastic, as many texts showed thematic and structural parallels beyond their national origin. This demonstrated a shift from the interest in 'place' (understood as socio-cultural location) towards a preoccupation with 'space' (understood as a global physical dimension). In contrast, however, very few studies are dedicated to the Fantastic across national and disciplinary borders. Furthermore, studies on the contemporary fantastic are scant, with a few exceptions (Horstkotte 2004; Grossman 2004). What could the reasons be? Perhaps the lack of available translations or the uneven quality of many of the literary works published in the past few decades might have discouraged scholars from embracing a more diverse corpus focused on a literary phenomenon and not limited by geographical borders.

The primary methodological principle when writing this book was to overcome these limitations and examine texts from diverse socio-cultural traditions. The works chosen here encompass foundational traditions of Fantastic, such as the French and British, as well as those of the more modern emergence, as seen in the Quebecois and Spanish texts. The analysis seeks to strike a balance between canonical French, Spanish or English-speaking 
authors - such as H.P. Lovecraft, J.L. Borges, Julio Cortázar, J.G. Ballard, John Barth, José B. Adolph, Jacques Sternberg, José María Merino, Juan José Millás and Cristina Fernández Cubas - and emerging voices of this narrative form, such as Peruvian Fernando Iwasaki, French writer Éric Faye, Quebecois Claude-Emmanuelle Yance, Jean-Paul Beaumier and Spanish authors Ángel Olgoso, José-Ferrer Bermejo, David Roas or Patricia Esteban Erlés. All these authors are well established writers of the Fantastic in their own countries but less well-known internationally (very often due to the lack of translations). My goal has been to bring these different traditions of the Fantastic together under the lens of spatiality. Each chapter concentrates on three or four texts taken as paradigmatic for the phenomenon I am seeking to conceptualise. In this manner, and in order to emphasise the thematic convergences within the specific frame of the postmodern Fantastic, national divergences have not been prioritised in the analysis.

The first chapter is of a theoretical-conceptual nature. It examines different approaches to the Fantastic, from the foundational (e.g. Todorov 1975) to more recent approaches (e.g. Roas 2012). It also offers a conceptual distinction between what I label 'the Fantastic of Place' (where the impossible happens in space) and 'the Fantastic of Space' (where the impossible element is spatial). This latter concept is the leitmotif of the next four chapters.

Returning to the initial metaphor of reality as 'an architecture', fictional reality is conceived here as an architectural object. In this 'architext' (expropriating Genette's play on words, 1979), the author founds a reality and erects a world with rhetorical tools, and the reader recreates this world in the act of reading. Paralleling narrative with an architectural creation, the following categories are four basic spatial 'stages' in the architectural configuration of any literary world and coincide with the basic phenomenological, 
philosophical and architectural categories of human space:

To start with, the writer - like the arkhitekton - creates a space for the characters and other objects. Each occupies a position, a place where every material object of this storyworld 'is'. The dimension of space is inextricably related to that of body and subject for the very simple reason that subjects need a physical space in which to be. When transferred to the fictional world, this means that characters need narrative space in which to exist. Therefore, Chapter II (BODY: (not) Being in Space) is dedicated to exploring the relationship between body and space, since the body is the referential axis through which the subject establishes distances between himself and his surroundings. This principle is central to the phenomenology of experience proposed by Maurice Merleau-Ponty (1945), which inspired an entire current of architectural thought. By also drawing from the spatial philosophy of Martin Heidegger (1951), this chapter combines the notion of physical position - in the textual world, corresponding to the emplacement of the character's body - with its existential dimension. To analyse how this relationship is transgressed, I refer to Frederic Jameson's (1991) and Anthony Vidler's (1991) analyses of postmodern architectural space as a weakening of the corporeal and existential experience. The resulting textual transgressions of bodies in space are therefore literal 'dis-locations' that lead to diverse modalities of subjects forced to redefine themselves in relation to their exceptional - fantastic - position in space.

Secondly, the architect-writer also needs to furnish the world; or to erect "paper monuments', to use Philippe Hamon's expression (1992). To differentiate, partition and distribute these elements, a system of defining spatial frames is established. The notion of 'boundary' is a fundamental referential element in constructing an articulated, realistic environment. As anthropology of space reminds us, the limes was one of the first principles through which primitive civilisations identified their space as their world. Chapter III (BOUNDARY: Liquid Constructions) is dedicated to transgressions of physical boundaries 
that define objects and buildings and the distances between them. In the context of the postmodern, this phenomenon ties in with what the architects Paul Virilio (1991) and Bernard Tschumi (1996) refer to as the 'liquefaction' of the postmodern built-environment. Several analogies will be noted between this notion of architectural 'liquefaction' and the examined textual spaces.

Thirdly, the elements in this textual world also need to be distributed into hierarchical levels. Just as the principle of hierarchy in architecture defines interlocking components, so too do the writer's architectural skills establish how the different spaces relate to each other as container and contained, part and whole: an object into a room; a room into a house; a house on a street, etc. The disruption of this apparently simple hierarchical logic is the subject of Chapter IV (HIERARCHY: Spaces Inside-Out). Since they have been widely analysed in postmodern literary criticism, the strategies of metalepsis and metafiction (disruption of fictional levels) are left aside here in order to focus on how transgressions of architectural hierarchies, including the interplay between referent and replica, bring the notion of referentiality to the fore.

Lastly, space as configured by the architect-writer encompasses a set of rules establishing how the components relate to each other. In its fullest sense, this space is a textual world conceived by characters as their reality. Drawing critically from Possible Worlds Theory, Chapter V (WORLD: Ontological Plurality) is centered on the transgression of the scheme of the one single, referential 'world' typically found in realistic texts.

Chapter I is a revised and extended version of earlier efforts published separately in Revista Letras\&Letras (2013b) and Brumal: Research Journal on the Fantastic (2013c). The concept of the 'threshold-sentence' in Chapter IV initially appeared in the volume Visiones de lo fantástico: aproximaciones teóricas (2013a). Finally, the study on "Los palafitos" in Chapter V is a revised and extended version of the essay "El espacio como sujeto fantástico: 
el ejemplo de "Los palafitos"' published in Pasavento: Revista de Estudios Hispánicos (2013b).

The challenge when writing this book was to avoid lists of isolated spatial metaphors and recurrent settings within the postmodern Fantastic. Neither did I want to provide a catalogue of impossible topologies. Instead, this work started as an exercise of abstraction to determine forms in which reality and space (factual and fictional) are co-dependent. In this way, the reverse task could also be carried out: identifying how space could transgress the impression of realism. As a result, these four suggested themes not only affect large numbers of narratives - thus broadening their applicability beyond the texts quoted - but, more importantly, they also embrace and provide a structure for derivative transgressions such as physical disappearance in space or of spaces, animations of buildings, or alterations of distances, volumes, and dimensions.

These four categories are neither mutually exclusive nor do they present a complete and finalised model for the topic at stake. Claiming that this structure covers the composition of human spatiality entirely would be a philosophical imposture; a limited number of abstract categories cannot resolve the complex nature of human space and its relationship with textual models of reality. Nevertheless, conscious of these limitations, I have wanted in this book to create a comprehensive systematisation of the relevance of literary space in order to construct and thus to transgress narrative realism. By being distinct and yet complementary, 'body', 'boundary', 'hierarchy' and 'word' provide coherence and multiple points of connection.

What role do fictional spaces have in our construction of experience and understanding of the world? What is our understanding of postmodern space? How does literature mediate in this understanding? How have different conceptions of space nurtured different fantastic traditions and how is this present in the postmodern Fantastic? What perspective on human spatiality does the literary Fantastic provide that is not provided by any 
other artistic form? These are the questions that haunt this book and, in order to explore them, I delve into literary analysis as well as into classical questions of space as appertaining to the fields of philosophy, urban studies and anthropology. Consequently, those anthropologists, sociologists and philosophers concerned with the dialogue between space and transgression, and between space and reality might find some inspiration in the following chapters. It might also appeal to those interested in how we understand, perceive and artistically interpret human spatiality in the postmodern context.

Finally, a small note on the chosen title. If architecture in the etymological sense is a foundation, a construction of a reality, 'the Architectural Void' seemed an appropriate metaphor for the phenomenon that this book seeks to systematise. The dimension of space in the following fantastic texts fails to provide reference, structure and meaning. On the contrary, space becomes a-referential, a-structural, illogical and disorienting: it weakens the impression of a consistent reality. Therefore, by transgressing the constructed realism within the text, all the examined spatial transgressions have one aspect in common: they attempt to unmask the frail foundations that we humans, precarious architects of our world, have laid to find orientation in our so-called reality. 